\title{
Prostacyclin Use Among Patients with Pulmonary Arterial Hypertension in the United States: A Retrospective Analysis of a Large Health Care Claims Database
}

\author{
Charles D. Burger, MD, FCCP; Janis A. Pruett, EdD, MSN, FNP-BC; Cassandra A. Lickert, MD; \\ Ariel Berger, MPH; Brian Murphy, MS; and William Drake, III, PharmD
}

\begin{abstract}
BACKGROUND: Prostacyclins play an important role in the management of pulmonary arterial hypertension (PAH). Intravenous prostacyclin was the first disease-specific treatment for patients with PAH. Subcutaneous and nonparenteral (oral or inhaled) formulations have subsequently become available. However, data are lacking on how these different prostacyclin formulations are being used in clinical practice.
\end{abstract}

OBJECTIVES: To (a) conduct retrospective analyses of a large U.S. health care claims database to describe the characteristics of patients with PAH initiating prostacyclin therapy, and (b) evaluate their treatment patterns, health care resource use, and associated costs.

METHODS: Truven Commercial and Medicare databases were used to define annual cohorts of adults with PAH between January 1, 2010, and October 31, 2015. These patients were identified based on claims with ICD-9-CM diagnoses indicative of PAH (codes 416.0 or 416.8 ) and claims for PAH-specific medications and PAH-related procedures. Patients with evidence of receiving a prostacyclin were identified, and prostacyclin use was categorized as parenteral versus nonparenteral. Health care costs were assessed alternatively employing an all-cause and PAH-related perspective.

RESULTS: Of 13,633 adults with identified PAH, 3,006 (22.0\%) received a prostacyclin during at least 1 year of the study period, and annual prevalence of prostacyclin use ranged from $19.9 \%$ to $22.6 \%$. Across calendar years, the median age of prostacyclin users ranged from 56 to 58 years, and $71.9 \%-75.8 \%$ were female. Among prostacyclin users, parenteral prostacyclin use declined from $63.2 \%$ in 2010 to $46.5 \%$ in 2015 , while use of nonparenteral prostacyclins increased from $39.7 \%$ to $56.2 \%$ over the same period (both $P<0.001)$. Few patients $(2.7 \%-4.1 \%)$ received both parenteral and nonparenteral formulations in a given calendar year. Among patients using prostacyclins, receipt of other PAH-specific medications increased from $62.1 \%$ in 2010 to $79.2 \%$ in 2015 . Comparing the 6 months preceding the first prostacyclin prescription (any formulation) to the 6 months subsequent, mean overall health care costs rose from $\$ 61,243$ to $\$ 119,283$, and PAH-related health care costs increased from $\$ 58,815$ to $\$ 116,661$, driven mainly by PAH-specific medications, spending on which increased from $\$ 15,053$ to $\$ 73,705$ (all $P<0.001$ ).

CONCLUSIONS: While overall use of prostacyclins was relatively constant from 2010 to 2015, our findings revealed a shift from parenteral to nonparenteral formulations, coupled with increased prescribing of PAH-related medications from other drug classes. Further research is needed to better understand how these changes in patterns of prostacyclin use affect levels of health care resource utilization and costs and patients' overall quality of life.

J Manag Care Spec Pharm. 2018;24(3):291-302

Copyright $\odot 2018$, Academy of Managed Care Pharmacy. All rights reserved.

\section{What is already known about this subject}

Retrospective analyses of claims databases have reported low rates of prostacyclin use among patients with pulmonary arterial hypertension (PAH) before 2009.

Treatment options for PAH have expanded rapidly since 2009.

\section{What this study adds}

While the overall proportion of $\mathrm{PAH}$ patients receiving prostacyclins has been consistent, there has been a shift away from parenteral formulations to newer, nonparenteral prostacyclins. Total costs increased following prostacyclin initiation, primarily attributable to the product costs of prostacylins, and costs of inpatient and outpatient care tended to remain consistent or decrease over time.

One third and one half of patients newly started on parenteral and nonparenteral prostacylins, respectively, augmented treatment with PAH-specific agents from different drug classes.

$\mathrm{P}$ ulmonary arterial hypertension (PAH) is a rare and debilitating chronic disease of the pulmonary vasculature, characterized by vascular proliferation and remodeling of the small pulmonary arteries. ${ }^{1}$ In the absence of effective treatment, these pathological changes result in a progressive increase in pulmonary vascular resistance, potentially leading to right-heart failure and premature death. ${ }^{1}$

Medical management of PAH is based on therapy with 1 or more drugs that target its underlying dysfunctional pathways., ${ }^{2,3}$ The first PAH-specific agent to be approved was intravenous (IV) epoprostenol, a synthetic analog of prostaglandin I2 (also known as prostacyclin), which remains the gold standard for treating patients with advanced disease. ${ }^{4}$ Since epoprostenol, other prostacyclins have been approved for PAH by the U.S. Food and Drug Administration (FDA), including most recently a formulation of IV epoprostenol with enhanced stability at room temperature, as well as subcutaneous treprostinil and nonparenteral agents such as inhaled and oral treprostinil and inhaled iloprost. ${ }^{5}$ The prostacyclin pathway is also targeted by the novel oral prostacyclin receptor agonist, selexipag, which was approved by the FDA in December $2015 .{ }^{6}$ In addition, 
PAH-specific agents are currently available from other drug classes, as follows: endothelin receptor antagonists (ERAs; oral ambrisentan, bosentan, and macitentan); phosphodiesterase type-5 inhibitors (PDE-5i's; oral sildenafil and tadalafil); and the soluble guanylate cyclase (sGC) stimulator, oral riociguat.,

IV epoprostenol is the only drug therapy to have shown a survival benefit in a controlled trial, ${ }^{7}$ as subsequent placebocontrolled trials with other agents assessing mortality as an endpoint could not ethically be performed. ${ }^{8}$ Consequently, the most recent PAH clinical practice guidelines continue to recommend parenteral prostacyclins for high-risk cases in World Health Organization Functional Class (FC) IV as well as those patients in FC III who have rapid disease progression or other markers of a poor prognosis. ${ }^{2,3}$ In the United States, nonparenteral prostacyclins are currently recommended primarily in combination with agents from other drug classes for PAH patients in FC III or IV. ${ }^{2}$

Several retrospective claims database studies reported PAH treatment patterns in the United States, ${ }^{9-12}$ but those studies covered time periods before 2009, preceding the availability of the most recently approved agents, namely, inhaled and oral treprostinil, macitentan, riociguat, and selexipag. ${ }^{5,13}$ Similarly, data are lacking to identify whether the prescribing of prostacyclins has increased following the availability of more convenient inhaled and oral forms.

Among patients receiving prostacyclins, even less is known about the real-world use of combination therapy with drugs from different classes, a concept that is increasingly prominent in clinical practice guidelines. ${ }^{2,3,14}$ There is limited real-world evidence on the use of parenteral prostacyclins in the United States other than that based on enrollees in REVEAL (Registry to Evaluate Early And Long-Term PAH Disease Management)the largest prospective registry of $\mathrm{PAH}$ patients-in which approximately $43 \%$ of patients were receiving a parenteral prostacyclin and $14 \%$ a nonparenteral prostacyclin at time of death (either alone or in combination with an ERA or a PDE-5i). ${ }^{15}$ To address this information gap, this study was conducted to assess relatively current patterns of use of prostacyclins and other PAH-specific agents in a large sample of commercially insured adult Americans.

\section{Methods}

\section{Data Source}

The data sources for this study were the Truven (formerly Medstat) MarketScan Commercial Claims and Encounters Database and the Truven MarketScan Medicare Supplemental Coordination of Benefits Database. These large databases are nationally representative for commercially insured health plan enrollees with medical and pharmacy coverage, have been widely used to conduct retrospective observational research, and are the basis for more than 1,100 peer-reviewed articles published since $1990,{ }^{16}$ including some specific to PAH. $.11,17,18$
The databases included approximately 15 million covered lives during the study period, which spanned January 1, 2010-October 31, 2015 (the latest date for which data were available at the time of analysis). These data have been anonymized and are fully compliant with the Health Insurance Portability and Accountability Act Privacy Rule.

Available demographic and insurance data included age, gender, coverage type, and dates of plan eligibility. Medical claims data available for analysis included disease diagnoses (recorded as International Classification of Diseases, Ninth Revision, Clinical Modification [ICD-9-CM] codes); procedures (ICD-9-CM, Current Procedural Terminology-4, and Healthcare Common Procedure Coding System codes); provider specialty; and charged and reimbursed amounts for services.

Pharmacy claims data included details of dispensed drugs (with identification by National Drug Code numbers) and reimbursed amounts.

\section{Study Design and Cohort Selection}

Claims data do not contain sufficient detail, such as findings from right heart catheterization (RHC), to confirm a PAH diagnosis. In the absence of such data, and given the nonspecificity of the ICD-9-CM diagnostic codes for PAH (vs. other forms of pulmonary hypertension $[\mathrm{PH}]),{ }^{19}$ an algorithm was used to identify patients with PAH that was based on similar methods used in previous retrospective database studies in this therapeutic area. ${ }^{9,17,20,21}$

To increase the sensitivity of ascertainment, broad criteria were applied in the first step, whereby data were extracted from the Truven databases for patients with a diagnosis suggestive of PAH (ICD-9-CM code 416.0 or 416.8) or nonspecific pulmonary heart disease (ICD-9-CM code 416.9); any claim for a PAH-related procedure (RHC or left heart catheterization, cardiac surgery, echocardiogram, and lung/heart-lung transplants); or any prescription for a PAH-specific medication (prostacyclin, prostacyclin receptor agonist, ERA, PDE-5i, and sGC). Database codes are presented in Appendix A (available in online article). No selexipag use was ascertained, since this agent became available after the study period.

Two sets of analyses were performed, one that included all patients with $\mathrm{PAH}$ identified in any given year of the study period ("prevalence-based"), the other focused on PAH patients newly initiating prostacyclin treatment ("incidencebased"). For the prevalence-based analyses, patients with PAH were ascertained on the basis of any 1 of the following algorithms: (a) 2 or more outpatient claims with PAH diagnoses (ICD-9-CM codes 416.0 or 416.8 ) at least 30 days apart and at least 1 prescription for a PAH-specific medication; (b) at least 1 inpatient claim with a PAH diagnosis and at least 1 prescription for a PAH-specific medication; (c) at least 1 outpatient claim with a PAH diagnosis and 2 or more prescriptions for 


\section{Prostacyclin Use Among Patients with Pulmonary Arterial Hypertension in the United States: A Retrospective Analysis of a Large Health Care Claims Database}

\section{TABLE 1 Ascertainment of Prevalence-Based Cohorts of PAH Patients, by Year}

\begin{tabular}{|c|c|c|c|c|c|c|c|c|}
\hline \multirow[b]{2}{*}{ Number (\%) of patients with: } & \multicolumn{8}{|c|}{ Year } \\
\hline & 2010 & 2011 & 2012 & 2013 & 2014 & $2015^{a}$ & $2010-$ & $P$ Value \\
\hline $\begin{array}{l}\geq 2 \text { outpatient claims with diagnoses of } \mathrm{PAH} \geq 30 \text { days apart and } \\
\geq 1 \text { claim for a PAH-specific medication }\end{array}$ & 3,645 & 4,470 & 4,573 & 4,056 & 4,067 & 2,800 & 12,073 & - \\
\hline $\begin{array}{l}\geq 1 \text { inpatient claim with diagnoses of PAH and } \\
\geq 1 \text { claim for a PAH-specific medication }\end{array}$ & 1,662 & 1,977 & 2,008 & 1,820 & 1,792 & 1,007 & 7,766 & - \\
\hline $\begin{array}{l}\geq 1 \text { outpatient claim with diagnoses of PAH and } \\
\geq 2 \text { claims for PAH-specific medications }\end{array}$ & 3,972 & 4,821 & 5,008 & 4,394 & 4,374 & 3,265 & 12,538 & - \\
\hline $\begin{array}{l}\text { Claim for RHC followed within 1-60 days by } \geq 1 \text { claim with } \\
\text { PAH diagnosis, then } \geq 1 \text { claim for a PAH-specific medication }\end{array}$ & 1,108 & 1,301 & 1,335 & 1,116 & 1,032 & 607 & 5,397 & - \\
\hline Total with evidence of PAH & 4,525 & 5,444 & 5,576 & 4,971 & 4,841 & 3,543 & 14,430 & - \\
\hline Aged $\geq 18$ years & 4,298 & 5,166 & 5,315 & 4,733 & 4,592 & 3,358 & 13,633 & - \\
\hline Received prostacyclin & $\begin{array}{r}905 \\
(21.1) \\
\end{array}$ & $\begin{array}{l}1,119 \\
(21.7)\end{array}$ & $\begin{array}{l}1,109 \\
(20.9)\end{array}$ & $\begin{array}{r}960 \\
(20.3) \\
\end{array}$ & $\begin{array}{l}1,038 \\
(22.6)\end{array}$ & $\begin{array}{r}667 \\
(19.9)\end{array}$ & $\begin{array}{l}3,006 \\
(22.0)\end{array}$ & 0.637 \\
\hline Received ERA & $\begin{array}{l}2,019 \\
(47.0) \\
\end{array}$ & $\begin{array}{l}2,318 \\
(44.9) \\
\end{array}$ & $\begin{array}{l}2,311 \\
(43.5)\end{array}$ & $\begin{array}{l}1,945 \\
(41.1)\end{array}$ & $\begin{array}{l}1,910 \\
(41.6) \\
\end{array}$ & $\begin{array}{l}1,558 \\
(46.4)\end{array}$ & $\begin{array}{l}5,669 \\
(41.6)\end{array}$ & 0.002 \\
\hline Received PDE-5i & $\begin{array}{l}2,826 \\
(65.8)\end{array}$ & $\begin{array}{l}3,531 \\
(68.4)\end{array}$ & $\begin{array}{l}3,804 \\
(71.6)\end{array}$ & $\begin{array}{l}3,524 \\
(74.5)\end{array}$ & $\begin{array}{r}3,322 \\
(72.3)\end{array}$ & $\begin{array}{l}2,443 \\
(72.8)\end{array}$ & $\begin{array}{r}10,111 \\
(74.2)\end{array}$ & $<0.001$ \\
\hline
\end{tabular}

aThrough October 31, 2015, only.

$E R A=$ endothelin receptor antagonist; $P A H=$ pulmonary arterial hypertension; $P D E-5 i=$ phosphodiesterase type -5 inhibitor; $R H C=$ right heart catheterization

PAH-specific medications; or (d) a claim for RHC followed by at least 1 claim with a PAH diagnosis followed by at least 1 prescription for a PAH-specific medication, where the claims for $\mathrm{PAH}$ and the PAH-specific medication were both required to be within 60 days of the date of RHC. Six calendar-year cohorts of prevalent PAH patients were constructed across the 2010-2015 study period, each consisting of all patients meeting any 1 of the aforementioned 4 algorithms in the corresponding year. Within a given calendar-year cohort, patients younger than 18 years at the start of the year were excluded.

For the incidence-based analyses, all patients with evidence of receipt of a prostacyclin (any form) during the study period were identified. The earliest date of receipt of prostacyclin during this period was designated the "index date," and to allow identification of first use of a prostacyclin, patients were required to have a minimum of 6 months of continuous enrollment in their health plan before this date. Patients also were required to have any 1 of the following: (a) 1 or more claims with a PAH diagnosis within the 3-month period before index date; (b) at least 1 prescription for a PAH-specific medication other than a prostacyclin within this 3-month period; or (c) 1 or more claims with a PAH diagnosis within the 4-week period following the index date.

\section{Statistical Analysis}

Descriptive statistics were used to describe patients' baseline characteristics and the prescribing patterns for PAH-specific agents across the study period, using counts and percentages for discrete variables, and mean and standard deviation or median and interquartile range for continuous variables. The
Charlson Comorbidity Index (CCI) was constructed from all relevant conditions (each assessed with appropriate ICD-9-CM codes) using standard methods. ${ }^{22,23}$

Cochran-Armitage tests were used to assess the statistical significance of trends over time in receipt of prostacyclins, ERAs, PDE-5i's, and sGC. Trends in use of these agents were assessed for each therapeutic class (e.g., prostacyclins; ERAs) as well as for selected agents within each class (e.g., epoprostenol, iloprost, treprostinil; ambrisentan, bosentan, macitentan). As necessary, these analyses also were conducted on specific branded products and their generic counterparts (e.g., the trend of epoprostenol prescribing was assessed, as were the trends in prescribing of Flolan [original IV epoprostenol], Veletri [room-temperature-stable formulation], and generic epoprostenol). Two-sided $P$ values were used for each of these tests, as there were no a priori hypotheses concerning whether prescribing of any particular agent(s) increased or decreased over the study period.

For the incidence-based analyses, health care costs were assessed alternatively employing a total (i.e., all-cause) and PAH-related perspective. The former was based on all claims for medical care (inpatient or outpatient) and all prescription pharmacotherapy; the latter, on all claims involving a PAH diagnosis, PAH-specific medications, ancillary PAH-related therapies (calcium channel blockers, diuretics, anticoagulants, cardiac glycosides, and oxygen), or PAH-related procedures. Reimbursed amounts were used as a proxy for costs and were computed as the combined amounts paid by health plans and patients (e.g., copays and coinsurance). 


\section{Prostacyclin Use Among Patients with Pulmonary Arterial Hypertension in the United States: A Retrospective Analysis of a Large Health Care Claims Database}

\section{TABLE 2 Characteristics of PAH Patients Using $\geq 1$ Prostacyclin, by Year}

\begin{tabular}{|c|c|c|c|c|c|c|c|}
\hline \multirow[b]{2}{*}{ Characteristic } & \multicolumn{7}{|c|}{ Year } \\
\hline & 2010 & 2011 & 2012 & 2013 & 2014 & \multicolumn{2}{|c|}{$2015^{a}$} \\
\hline Number & 905 & 1,119 & 1,109 & 960 & 1,038 & \multicolumn{2}{|c|}{667} \\
\hline \multicolumn{8}{|l|}{ Age, years } \\
\hline Mean (SD) & $55.0 \quad(14.0)$ & $56.8 \quad(13.9)$ & $56.3 \quad(13.9)$ & $56.4 \quad(14.1)$ & $56.5 \quad(14.2)$ & 55.8 & $(14.7)$ \\
\hline Median (IQR) & $56(46-64)$ & $58(48-66)$ & $57(48-65)$ & $57(47-66)$ & $58(48-66)$ & 57 & $(47-65)$ \\
\hline Range & $(18-89)$ & $(18-90)$ & $(18-90)$ & $(18-92)$ & $(18-93)$ & & -94) \\
\hline \multicolumn{8}{|c|}{ Duration of study enrollment in calendar year, months } \\
\hline Mean (SD) & $10.7 \quad(2.7)$ & $10.8 \quad(2.8)$ & $10.9 \quad(2.5)$ & $10.8 \quad(2.7)$ & 10.7 & 8.2 & $(2.1)$ \\
\hline Median (IQR) & $12(12-12)$ & $12(12-12)$ & $12(12-12)$ & $12(12-12)$ & $12(11-12)$ & 9 & $(7-10)$ \\
\hline \multicolumn{8}{|l|}{ Gender, n (\%) } \\
\hline Male & $221 \quad(24.4)$ & $314 \quad(28.1)$ & $290 \quad(26.1)$ & $232(24.2)$ & $255 \quad(24.6)$ & 165 & $(24.7)$ \\
\hline Female & $684 \quad(75.6)$ & $805 \quad(71.9)$ & $819 \quad(73.9)$ & $728 \quad(75.8)$ & $783 \quad(75.4)$ & 502 & $(75.3)$ \\
\hline \multicolumn{8}{|l|}{ Geographic region, $\mathrm{n}(\%)$} \\
\hline Northeast & $166 \quad(18.3)$ & $235 \quad(21.0)$ & $206 \quad(18.6)$ & $191 \quad(19.9)$ & $208 \quad(20.0)$ & 133 & (19.9) \\
\hline North Central & $261 \quad(28.8)$ & $303 \quad(27.1)$ & $276 \quad(24.9)$ & $245 \quad(25.5)$ & $248 \quad(23.9)$ & 170 & $(25.5)$ \\
\hline South & $322 \quad(35.6)$ & $368 \quad(32.9)$ & $400 \quad(36.1)$ & $304 \quad(31.7)$ & $360 \quad(34.7)$ & 277 & $(41.5)$ \\
\hline West & $145 \quad(16.0)$ & $188 \quad(16.8)$ & $202 \quad(18.2)$ & $191 \quad(19.9)$ & $201 \quad(19.4)$ & 86 & $(12.9)$ \\
\hline Unknown/missing & $11 \quad(1.2)$ & $25 \quad(2.2)$ & $25 \quad(2.3)$ & $29 \quad(3.0)$ & $21 \quad(2.0)$ & 1 & $(0.1)$ \\
\hline \multicolumn{8}{|l|}{ Payer type, n (\%) } \\
\hline Commercial & $694 \quad(76.7)$ & $790 \quad(70.6)$ & $791 \quad(71.3)$ & $679 \quad(70.7)$ & $734 \quad(70.7)$ & 487 & $(73.0)$ \\
\hline Medicare & $211 \quad(23.3)$ & $329 \quad(29.4)$ & $318 \quad(28.7)$ & $281 \quad(29.3)$ & $304 \quad(29.3)$ & 180 & $(27.0)$ \\
\hline \multicolumn{8}{|l|}{ Charlson Comorbidity Index } \\
\hline Mean (SD) & $(2.2)$ & $(2.2)$ & $(2.2)$ & $(2.3)$ & $(2.2)$ & 2.8 & $(2.0)$ \\
\hline Median (IQR) & $2 \quad(1-4)$ & $(2-4)$ & $(1-4)$ & $(2-4)$ & $(2-4)$ & 2 & $(1-4)$ \\
\hline \multicolumn{8}{|l|}{ Comorbidities, n (\%) } \\
\hline Depressive disorders & 132 (14.6) & $139 \quad(12.4)$ & $171 \quad(15.4)$ & $161 \quad(16.8)$ & $174 \quad(16.8)$ & 84 & (12.6) \\
\hline Anxiety disorders & $97 \quad(10.7)$ & $(8.7)$ & $124 \quad(11.2)$ & $129 \quad(13.4)$ & $150 \quad(14.5)$ & 67 & $(10.0)$ \\
\hline Sleep disorders & $125 \quad(13.8)$ & $177 \quad(15.8)$ & $187 \quad(16.9)$ & $144 \quad(15.0)$ & $155 \quad(14.9)$ & 100 & $(15.0)$ \\
\hline Cerebrovascular disease & $76 \quad(8.4)$ & $108 \quad(9.7)$ & $96 \quad(8.7)$ & $80 \quad(8.3)$ & $92 \quad(8.9)$ & 48 & $(7.2)$ \\
\hline Peripheral vascular disease & $(5.3)$ & $(7.8)$ & $(6.8)$ & $(6.5)$ & $(5.9)$ & 28 & $(4.2)$ \\
\hline Coronary heart disease & $232 \quad(25.6)$ & $298 \quad(26.6)$ & $280 \quad(25.2)$ & $226 \quad(23.5)$ & $271 \quad(26.1)$ & 161 & $(24.1)$ \\
\hline Atrial fibrillation & $\begin{array}{ll}0 & (0.0)\end{array}$ & $\begin{array}{ll}0 & (0.0)\end{array}$ & $\begin{array}{ll}0 & (0.0)\end{array}$ & $\begin{array}{ll}0 & (0.0)\end{array}$ & $0 \quad(0.0)$ & 0 & $(0.0)$ \\
\hline Raynaud's syndrome & $(0.0)$ & $(0.0)$ & $(0.0)$ & $(0.0)$ & $(0.0)$ & 0 & $(0.0)$ \\
\hline Hematological conditions & $(0.8)$ & $(0.6)$ & $(0.4)$ & $(0.9)$ & $(1.1)$ & 9 & (1.3) \\
\hline Liver disease & $137 \quad(15.1)$ & $143 \quad(12.8)$ & $149 \quad(13.4)$ & $131 \quad(13.6)$ & $135 \quad(13.0)$ & 66 & $(9.9)$ \\
\hline Renal disease & $390 \quad(43.1)$ & $458 \quad(40.9)$ & $469 \quad(42.3)$ & $410 \quad(42.7)$ & $458 \quad(44.1)$ & 263 & (39.4) \\
\hline Diabetes & $204 \quad(22.5)$ & $289 \quad(25.8)$ & $281 \quad(25.3)$ & $241 \quad(25.1)$ & $271 \quad(26.1)$ & 170 & $(25.5)$ \\
\hline Neoplasms & $158 \quad(17.5)$ & $210 \quad(18.8)$ & $196 \quad(17.7)$ & $171 \quad(17.8)$ & $206 \quad(19.8)$ & 92 & (13.8) \\
\hline
\end{tabular}

aThrough October 31, 2015, only.

$I Q R=$ interquartile range; $P A H=$ pulmonary arterial hypertension; $S D=$ standard deviation

All costs were adjusted to 2015 U.S. dollars using the medical care component of the Consumer Price Index.. ${ }^{24}$ In the incident prostacyclin new-start cohort, patterns of health care resource utilization and costs were compared between the 6-month periods before and after initiation of prostacyclin therapy, using paired t-tests for continuous variables and McNemar's test for binary data. In these analyses, patients served as their own controls (i.e., were compared against themselves) over relatively short time periods, and thus there was no need to further account for potential confounding.

\section{Results}

\section{Prevalence-Based Analyses}

PAH-Specific Medication Prescribing Patterns. A total of 14,430 patients had evidence of PAH during the study period, of whom 13,633 were at least 18 years of age and were included in the prevalent PAH cohort. Of these, only 3,006 (22.0\%) patients received a prostacyclin (Table 1). The most commonly prescribed drug class was PDE-5i, used by $74.2 \%$ of patients; fewer than half (41.6\%) received an ERA. 


\section{Prostacyclin Use Among Patients with Pulmonary Arterial Hypertension in the United States: A Retrospective Analysis of a Large Health Care Claims Database}

TABLE 3 Utilization of PAH-Related Therapies by Patients Using $\geq 1$ Prostacyclins, by Year

\begin{tabular}{|c|c|c|c|c|c|c|c|}
\hline \multirow[b]{2}{*}{ Medication, n patients (\%) } & \multicolumn{6}{|c|}{ Year } & \multirow[b]{2}{*}{$P$ Value } \\
\hline & 2010 & 2011 & 2012 & 2013 & 2014 & $2015^{a}$ & \\
\hline Prostacyclins & $905(100.0)$ & $1,119(100.0)$ & $1,109(100.0)$ & $960(100.0)$ & $1,038(100.0)$ & $667(100.0)$ & \\
\hline Epoprostenol & $283 \quad(31.3)$ & $290 \quad(25.9)$ & $268 \quad(24.2)$ & $237 \quad(24.7)$ & $247 \quad(23.8)$ & $129 \quad(19.3)$ & $<0.001$ \\
\hline Flolan & $\begin{array}{ll}5 & (0.6) \\
\end{array}$ & $5 \quad(0.4)$ & $5 \quad(0.5)$ & $4 \quad(0.4)$ & $4 \quad(0.4)$ & $1 \quad(0.1)$ & 0.269 \\
\hline Veletri & $(0.1)$ & $(0.5)$ & $(0.4)$ & $(1.1)$ & $(2.3)$ & $(2.8)$ & $<0.001$ \\
\hline Generic & $2 \quad(0.2)$ & $\begin{array}{ll}0 & (0.0)\end{array}$ & $(0.0)$ & $(0.0)$ & $(0.0)$ & $(0.1)$ & 0.454 \\
\hline Iloprost (Ventavis) & $239 \quad(26.4)$ & $205 \quad(18.3)$ & $156 \quad(14.1)$ & $116 \quad(12.1)$ & $(9.2)$ & $(7.3)$ & $<0.001$ \\
\hline Treprostinil & $456 \quad(50.4)$ & $692 \quad(61.8)$ & $742 \quad(66.9)$ & $660 \quad(68.8)$ & $744 \quad(71.7)$ & $514 \quad(77.1)$ & $<0.001$ \\
\hline Remodulin (IV and SC) & $329 \quad(36.4)$ & $359 \quad(32.1)$ & $372(33.5)$ & $313 \quad(32.6)$ & $331 \quad(31.9)$ & $201 \quad(30.1)$ & 0.023 \\
\hline Tyvaso (inhaled) & $132 \quad(14.6)$ & $359 \quad(32.1)$ & $395 \quad(35.6)$ & $366 \quad(38.1)$ & $388 \quad(37.4)$ & $256 \quad(38.4)$ & $<0.001$ \\
\hline Orenitram (oral) & $\begin{array}{ll}0 & (0.0)\end{array}$ & $0 \quad(0.0)$ & $0 \quad(0.0)$ & $\begin{array}{ll}0 & (0.0)\end{array}$ & $58 \quad(5.6)$ & $85 \quad(12.7)$ & $<0.001$ \\
\hline Parenteral prostacyclin & $572 \quad(63.2)$ & $613 \quad(54.8)$ & $611 \quad(55.1)$ & $522 \quad(54.4)$ & $550 \quad(53.0)$ & $310 \quad(46.5)$ & $<0.001$ \\
\hline Nonparenteral prostacyclin & $359 \quad(39.7)$ & $549 \quad(49.1)$ & $543(49.0)$ & $474 \quad(49.4)$ & $518 \quad(49.9)$ & $375 \quad(56.2)$ & $<0.001$ \\
\hline Parenteral and nonparenteral prostacyclin & $26 \quad(2.9)$ & $43 \quad(3.8)$ & $(4.1)$ & $(3.8)$ & $(2.9)$ & $(2.7)$ & 0.446 \\
\hline Other PAH medications & $562 \quad(62.1)$ & $733(65.5)$ & $741 \quad(66.8)$ & $663 \quad(69.1)$ & $706 \quad(68.0)$ & $528 \quad(79.2)$ & $<0.001$ \\
\hline ERA & $385 \quad(42.5)$ & $493 \quad(44.1)$ & $486 \quad(43.8)$ & $443 \quad(46.1)$ & $481 \quad(46.3)$ & $366 \quad(54.9)$ & $<0.001$ \\
\hline Ambrisentan & $126 \quad(13.9)$ & $192 \quad(17.2)$ & $229 \quad(20.6)$ & $210 \quad(21.9)$ & $217 \quad(20.9)$ & $172 \quad(25.8)$ & $<0.001$ \\
\hline Bosentan & $264 \quad(29.2)$ & $312 \quad(27.9)$ & $266 \quad(24.0)$ & $232 \quad(24.2)$ & $199 \quad(19.2)$ & $97 \quad(14.5)$ & $<0.001$ \\
\hline Macitentan & $\begin{array}{ll}0 & (0.0)\end{array}$ & $\begin{array}{ll}0 & (0.0)\end{array}$ & $0 \quad(0.0)$ & $\begin{array}{ll}7 & (0.7)\end{array}$ & $119 \quad(11.5)$ & $117 \quad(17.5)$ & $<0.001$ \\
\hline PDE-5i & $423 \quad(46.7)$ & $562 \quad(50.2)$ & $599 \quad(54.0)$ & $542 \quad(56.5)$ & $568 \quad(54.7)$ & $413 \quad(61.9)$ & $<0.001$ \\
\hline Sildenafil & $334 \quad(36.9)$ & $380 \quad(34.0)$ & $339 \quad(30.6)$ & $269 \quad(28.0)$ & $267 \quad(25.7)$ & $189 \quad(28.3)$ & $<0.001$ \\
\hline Revatio & $334 \quad(36.9)$ & $380 \quad(34.0)$ & $333(30.0)$ & $(7.9)$ & $50 \quad(4.8)$ & $(2.5)$ & $<0.001$ \\
\hline Generic & $0 \quad(0.0)$ & $0 \quad(0.0)$ & $117 \quad(10.6)$ & $225 \quad(23.4)$ & $230 \quad(22.2)$ & $174 \quad(26.1)$ & $<0.001$ \\
\hline Tadalafil (Adcirca) & $118 \quad(13.0)$ & $213 \quad(19.0)$ & $284 \quad(25.6)$ & $289 \quad(30.1)$ & $314 \quad(30.3)$ & $234 \quad(35.1)$ & $<0.001$ \\
\hline sGC & $0 \quad(0.0)$ & $0 \quad(0.0)$ & $(0.0)$ & $(1.3)$ & $(4.3)$ & $38 \quad(5.7)$ & $<0.001$ \\
\hline Exactly 1 of the above 3 categories & $316 \quad(34.9)$ & $411 \quad(36.7)$ & $397 \quad(35.8)$ & $333 \quad(34.7)$ & $330 \quad(31.8)$ & $246 \quad(36.9)$ & 0.383 \\
\hline$\geq 2$ of the above 3 categories & $246 \quad(27.2)$ & $322(28.8)$ & $344 \quad(31.0)$ & $330 \quad(34.4)$ & $376 \quad(36.2)$ & $282 \quad(42.3)$ & $<0.001$ \\
\hline
\end{tabular}

Prostacyclin use was relatively constant from 2010 to 2015, ranging between $19.9 \%$ in 2015 and $22.6 \%$ in $2014(P=0.637$ for comparison across all calendar-year cohorts). Although the trend was not linear, there was an overall increase in prescribing of PDE-5i's from $65.8 \%$ in 2010 to $72.8 \%$ in $2015(P<0.001)$. Conversely, ERA prescribing decreased from $47.0 \%$ in 2010 to $41.6 \%$ in 2014 (it rose again to $46.4 \%$ in 2015; $P=0.002$ ).

Characteristics of Prostacyclin Users. Demographic and clinical characteristics of the subset of the cohort who were prostacyclin users are reported in Table 2. The average patient was middle-aged, with both mean and median age in the midto-late 50 s across calendar years. Approximately three quarters of PAH patients using prostacyclins were female. A high level of comorbid conditions was observed, with similar high CCI values across years. The most common comorbidities across calendar years were renal disease (39.4\%-44.1\%), diabetes (22.5\%-26.1\%), and coronary heart disease (23.5\%-26.6\%).

Prescribing Patterns in Patients Receiving Prostacyclin. Among patients who were prostacyclin users, there was a decrease of nearly $10 \%$ in parenteral prostacyclin use and a corresponding $10 \%$ increase in nonparenteral prostacyclin use from 2010 to 2011, followed by relatively consistent distributions of parenteral versus nonparenteral prostacyclin use from 2011 through 2014, with an additional decrease in parenteral prostacyclin (and corresponding increase in nonparenteral prostacyclin) use from 2014 to 2015 (Table 3). The trend for decreasing parenteral and increasing nonparenteral prostacyclin use was statistically significant $(P<0.001)$.

In every year, the most commonly used prostacyclin was treprostinil, and there was a trend for increasing use of its inhaled formulation over time; in contrast, use of IV and subcutaneous treprostinil declined over time (all $P<0.001$ ). The first prescriptions for oral treprostinil were seen in 2014; it was used by $5.6 \%$ of patients who received a prostacyclin in that year and by $12.7 \%$ in 2015 .

Patients receiving prostacyclins also demonstrated increased use of PAH-specific agents of all other drug classes from $62.1 \%$ in 2010 to $79.2 \%$ in $2015(P<0.001)$. The first use of sGC in patients receiving prostacyclins was observed in 2013, and increased from $1.3 \%$ in that year to $5.7 \%$ in $2015(P<0.001)$. 


\section{Incidence-Based Analyses}

Demographic characteristics of prostacyclin new-starts were similar to those of the prevalent PAH cohort in that these patients were middle-aged, predominantly female, and had a high level of comorbidities, with a mean CCI of 2.4 (Table 4).

In the 3 months before the index date, $39.6 \%$ of prostacyclin new-starts had been hospitalized, 34.1\% had visited an emergency room (ER), and nearly all (96.4\%) had at least 1 office visit. A high proportion of these hospitalizations and office visits, and one half of ER visits, were PAH-related. Fiftythree percent of new-starts had received at least 1 PAH-specific medication other than a prostacyclin in the 3 months before initiating prostacyclin.

Demographic and clinical characteristics of the patients in the pre- versus post-index analysis are reported in Appendix B (available in online article). Relative to pre-index, the number of inpatient admissions decreased in the postinitiation period for both parenteral $(P<0.001)$ and nonparenteral new-starts $(P=0.041$; Table 5). Among patients newly started on nonparenteral prostacyclins, all-cause ER visits decreased in the postinitiation period $(P=0.003)$. In contrast, ER visits were relatively consistent from the pre- to post-index period among parenteral prostacyclin users $(P=0.251)$.

Across prostacyclin new-starts, mean 6-month aggregate health care costs nearly doubled from $\$ 61,243$ during the pre-index period to $\$ 119,283$ following therapy initiation $(P<0.001)$, nearly exclusively attributable to an increase for PAH-related health care costs, which rose from $\$ 58,815$ to $\$ 116,661 \quad(P<0.001)$. This increase in PAH-related health care costs was driven mainly by increased drug costs, which more than doubled their share of total costs from the pre-index period $(27.0 \%)$ to the post-index period $(64.0 \%)$. Since the costs of nondrug PAH-related health care decreased following prostacyclin initiation, the additional $\$ 58,804$ spent on $\mathrm{PAH}-$ related medications exceeded the overall increase of $\$ 57,846$ in total PAH-related health care costs.

Among subgroups of new-starts characterized by formulation of prostacyclin received on the index date, the mean overall and PAH-related health care costs more than doubled (pre- to post-index) among nonparenteral prostacyclin recipients, but increased by a factor of only 1.5 among parenteral prostacyclin recipients. The proportion of total PAH-related health care costs accounted for by drugs was higher in both the pre- and post-index periods for nonparenteral prostacyclin new-starts (38.1\% and $73.4 \%$, respectively) than for parenteral prostacyclin new-starts (11.7\% and $45.9 \%$, respectively). However, the relative difference in spending on PAH-related drugs for parenteral versus nonparenteral new-starts decreased from a factor of 2.8 in the pre-index period $(\$ 7,515$ vs. $\$ 21,164$, respectively) to a factor of 2.0 in the post-index period $(\$ 47,031$ vs. $\$ 92,086$, respectively).

\section{Discussion}

Drugs for PH ranked in the top 10 specialty therapy classes by spending per member per year for both commercially insured and Medicare enrollees in 2015, with total spending on these agents increasing by $18.1 \%$ and $21.4 \%$, respectively, compared with the previous year. ${ }^{25}$ Given these rising costs and the relatively large number of agents currently available (of which only IV epoprostenol included overall survival as one of the trial endpoints on which FDA approval was based), it is essential to determine how these agents are currently being used in clinical practice.

The main finding of the present study was that use of prostacyclins among patients with $\mathrm{PAH}$ has been relatively constant from 2010 to 2015, suggesting that the availability of nonparenteral formulations has not led clinicians to prescribe these agents to patients for whom they would previously have chosen an ERA or a PDE-5i. Indeed, rates of prostacyclin use were within the range reported in previous retrospective database studies by Copher et al. (2012), Said et al. (2012), Kirson et al. (2011), and Johnson et al. (2013). ${ }^{10,17,21,26}$

It is important to point out that the finding that fewer than one quarter of patients in this study used prostacyclins does not necessarily represent underprescribing. Recent guidelines recommend ERAs, PDE-5i's, or sGC, but not prostacyclins, for initial or second-line therapy of patients with $\mathrm{PAH}$ in FC II. ${ }^{2,3}$ Since it is impossible to determine the FC of PAH patients from retrospective claims data, ${ }^{27}$ there was no way to evaluate observed prescribing patterns relative to different FC subgroups among the study cohort.

Characteristics of our ascertained PAH cohort (i.e., average age, sex ratio, and comorbidity burden) were similar to those of patients with definitive PAH diagnoses (confirmed by RHC) enrolled in the REVEAL registry. ${ }^{28}$ If the FC distribution in our sample also mirrored that of REVEAL enrollees, $40.4 \%$ of whom were in FC I or II at enrollment, this may explain (at least in part) the high levels of use of nonprostacyclin PAHspecific therapies. Even if FC is known, there are additional factors that determine whether or not patients are appropriate candidates for prostacyclins. ${ }^{15}$ Indeed, in retrospective cohort studies, most patients not receiving parenteral prostacyclin at death (despite recommendations for use of IV epoprostenol in the most severe cases) died of non-PAH causes $^{29}$ or were unsuitable candidates for parenteral prostacyclin. ${ }^{30,31}$ Lastly, the use of PDE-5i's in patients not in group $1 \mathrm{PAH}$ or with mixed pre- and postcapillary PH cannot be excluded.

There was, however, a pronounced and significant shift from parenteral to nonparenteral formulations, primarily attributable to increased uptake of inhaled treprostinil, which was introduced in 2009. The shift may reflect the improved convenience and safety of nonparenteral formulations in comparison with parenteral prostanoids, which are associated with burdensome administration protocols, the risk for bloodstream 


\section{Prostacyclin Use Among Patients with Pulmonary Arterial Hypertension in the United States: A Retrospective Analysis of a Large Health Care Claims Database}

TABLE 4 Characteristics of Patients During 3 Months Before Initiating Prostacyclin Use, by Form of Prostacyclin Initiated

\begin{tabular}{|c|c|c|c|c|c|c|c|}
\hline Characteristic & $\begin{array}{c}\text { Parenteral } \\
\text { Prostacyclin } \\
\text { New-Starts }\end{array}$ & $\begin{array}{c}\text { Nonparenteral } \\
\text { Prostacyclin } \\
\text { New-Starts }\end{array}$ & $\begin{array}{c}\text { Any } \\
\text { Prostacyclin } \\
\text { New-Starts } \\
\text { (Fully Naive) }\end{array}$ & Characteristic & $\begin{array}{c}\text { Parenteral } \\
\text { Prostacyclin } \\
\text { New-Starts }\end{array}$ & $\begin{array}{c}\text { Nonparenteral } \\
\text { Prostacyclin } \\
\text { New-Starts }\end{array}$ & $\begin{array}{c}\text { Any } \\
\text { Prostacyclin } \\
\text { New-Starts } \\
\text { (Fully Naive) }\end{array}$ \\
\hline Number & 674 & 977 & 1,651 & PAH-related, n (\%) & $145 \quad(21.5)$ & $135 \quad(13.8)$ & $280 \quad(17.0)$ \\
\hline \multicolumn{4}{|l|}{ Age, years } & \multicolumn{4}{|l|}{ Number of visits } \\
\hline Mean (SD) & $54.0 \quad(13.5)$ & $60.7 \quad(13.8)$ & $57.9 \quad(14.1)$ & Mean (SD) & $0.3 \quad(0.6)$ & $0.2 \quad(0.5)$ & $0.2 \quad(0.5)$ \\
\hline Median (IQR) & $55(46-63)$ & $61(52-71)$ & $59(49-68)$ & Median (IQR) & $0 \quad(0-0)$ & $0 \quad(0-0)$ & $0 \quad(0-0)$ \\
\hline Range & $18-90$ & $18-90$ & $18-90$ & \multicolumn{4}{|l|}{ Office visits } \\
\hline \multicolumn{4}{|l|}{ Gender, n (\%) } & Any, n (\%) & $645 \quad(95.7)$ & $946 \quad(96.8)$ & $1,591 \quad(96.4)$ \\
\hline Male & $187 \quad(27.7)$ & $307 \quad(31.4)$ & $494 \quad(29.9)$ & \multicolumn{4}{|l|}{ Number of visits } \\
\hline Female & $487 \quad(72.3)$ & $670 \quad(68.6)$ & $1,157 \quad(70.1)$ & Mean (SD) & $8.5 \quad(6.9)$ & $8.1 \quad(5.8)$ & $8.3 \quad(6.3)$ \\
\hline \multicolumn{4}{|l|}{ Payer type, n (\%) } & Median (IQR) & $7 \quad(4-11)$ & $7 \quad(4-11)$ & $7 \quad(4-11)$ \\
\hline Commercial & $541 \quad(80.3)$ & $585 \quad(59.9)$ & $1,126 \quad(68.2)$ & PAH-related, n (\%) & $542 \quad(80.4)$ & $854 \quad(87.4)$ & $1,396 \quad(84.6)$ \\
\hline Medicare & $133(19.7)$ & $392 \quad(40.1)$ & $525 \quad(31.8)$ & \multicolumn{4}{|l|}{ Number of visits } \\
\hline \multicolumn{4}{|c|}{ Charlson Comorbidity Index } & Mean (SD) & $(4.6)$ & (2.4) & (3.5) \\
\hline Mean (SD) & $2.5 \quad(1.7)$ & $2.3 \quad(1.8)$ & $2.4 \quad(1.8)$ & Median (IQR) & $(1-4)$ & $(1-4)$ & $(1-4)$ \\
\hline Median (IQR) & $2 \quad(1-3)$ & $2 \quad(1-3)$ & $(1-3)$ & \multicolumn{4}{|l|}{ Health care costs, $\$$} \\
\hline \multicolumn{4}{|l|}{ Comorbidities, n (\%) } & \multicolumn{4}{|l|}{ PAH-related medications } \\
\hline Depressive disorders & $(9.1)$ & $(6.1)$ & (7.3) & Mean (SD) & $4,156 \quad(8,165)$ & $10,174 \quad(10,980)$ & $7,717 \quad(10,357)$ \\
\hline Anxiety disorders & $48 \quad(7.1)$ & $38 \quad(3.9)$ & $(5.2)$ & Median (IQR) & $0(0-3,820)$ & $5,432(0-20,105)$ & $1,492(0-16,222)$ \\
\hline Sleep disorders & $71 \quad(10.5)$ & $101 \quad(10.3)$ & $172(10.4)$ & \multicolumn{4}{|l|}{ PAH-related medical care } \\
\hline Cerebrovascular disease & $(4.6)$ & $(4.2)$ & $\begin{array}{rr}1 / 2 & (10.4) \\
72 & (4.4)\end{array}$ & Mean (SD) & $39,252(71,550)$ & $17,326 \quad(59,715)$ & $26,277 \quad(65,678)$ \\
\hline \multirow{2}{*}{$\begin{array}{l}\text { Peripheral vascular } \\
\text { disease }\end{array}$} & $22 \quad(3.3)$ & $37 \quad(3.8)$ & $\begin{array}{ll}72 & (4.4) \\
59 & (3.6)\end{array}$ & Median (IQR) & $\begin{array}{c}16,907 \\
(2,707-44,966)\end{array}$ & $\begin{array}{c}3,873 \\
(778-15,800)\end{array}$ & $\begin{array}{c}7,319 \\
(1,136-28,161)\end{array}$ \\
\hline & & & & \multicolumn{4}{|l|}{ Total PAH-related costs } \\
\hline Coronary heart disease & $172 \quad(25.5)$ & $214 \quad(21.9)$ & $386 \quad(23.4)$ & Mean (SD) & 43,408 & 27,500 & 33,994 \\
\hline Atrial fibrillation & $0 \quad(0.0)$ & $0 \quad(0.0)$ & $0 \quad(0.0)$ & & $(72$, & $(60,115)$ & $(65,692)$ \\
\hline Raynaud's syndrome & $(0.0)$ & $(0.0)$ & $(0.0)$ & Median (IQR) & 23,197 & 19,345 & 20,858 \\
\hline Hematological conditions & $12 \quad(1.8)$ & $(0.7)$ & $(1.2)$ & & $1,349)$ & $(5,577-32,005)$ & $(5,605-37,480)$ \\
\hline Liver disease & $64 \quad(9.5)$ & $(8.1)$ & $(8.7)$ & $2 d$ & & & \\
\hline Renal disease & $239 \quad(35.5)$ & $229 \quad(23.4)$ & $468 \quad(28.3)$ & & $\frac{7,643(27,944)}{2,538}$ & $\frac{5,954(14,071)}{2547}$ & $\frac{6,643(20,888)}{2530}$ \\
\hline Diabetes & $147 \quad(21.8)$ & $229 \quad(23.4)$ & $376 \quad(22.8)$ & an (IQR) & $\begin{array}{c}2,538 \\
(739-5,909)\end{array}$ & $\begin{array}{c}2,547 \\
(939-5,381)\end{array}$ & $\begin{array}{c}2,539 \\
(848-5,667)\end{array}$ \\
\hline Neoplasms & $66 \quad(9.8)$ & $116 \quad(11.9)$ & $182 \quad(11.0)$ & Total health care costs & & & \\
\hline Inpatient adm & & & & Mean (SD) & $51,051(79,070)$ & $33,453(62,449)$ & $40,637(70,227)$ \\
\hline Any, n (\%) & $403 \quad(59.8)$ & $250 \quad(25.6)$ & $653 \quad(39.6)$ & Median (IQR) & 29,180 & 23,310 & 24,997 \\
\hline Number of vi & & & & & $(11,885-58,717)$ & $(9,957-38,334)$ & $(10,516-44,776)$ \\
\hline Mean (SD) & $0.9 \quad(0.9)$ & $(0.6)$ & $(0.8)$ & Prostacyclins, n (\%) & NA & NA & NA \\
\hline Median (IQR) & $1 \quad(0-1)$ & $(0-1)$ & $(0-1)$ & Other PAH medication & $(\%)$ & & \\
\hline Length of stay, days & & & & ERA & $120(17.8)$ & $425(43.5)$ & $545(33.0)$ \\
\hline Mean (SD) & $\begin{array}{ll}5.5 & (7.6) \\
\end{array}$ & $(7.4)$ & $(7.7)$ & Ambrisentan & $44 \quad(6.5)$ & $183(18.7)$ & $227(13.7)$ \\
\hline Median (IQR) & $3 \quad(0-8)$ & $(0-1)$ & $(0-5)$ & Bosentan & $71(10.5)$ & $209(21.4)$ & $280(17.0)$ \\
\hline PAH-related, n (\%) & $377 \quad(55.9)$ & $214 \quad(21.9)$ & $591 \quad(35.8)$ & Macitentan & $\begin{array}{ll}6 & (0.9) \\
\end{array}$ & $37 \quad(3.8)$ & $43 \quad(2.6)$ \\
\hline Number of visits & & & & PDE-5i & $172(25.5)$ & $475(48.6)$ & $647(39.2)$ \\
\hline Mean (SD) & $0.7 \quad(0.8)$ & $(0.6)$ & $(0.7)$ & Sildenafil & $100(14.8)$ & $253(25.9)$ & $353(21.4)$ \\
\hline Median (IQR) & $1 \quad(0-1)$ & $0 \quad(0-0)$ & $(0-1)$ & Revatio & $78(11.6)$ & $178(18.2)$ & $256(15.5)$ \\
\hline Length of stay, days & & & & Generic & $23 \quad(3.4)$ & $76 \quad(7.8)$ & $99 \quad(6.0)$ \\
\hline Mean (SD) & $5.4 \quad(7.6)$ & $(7.4)$ & $(7.7)$ & Tadalafil (Adcirca) & $74(11.0)$ & $228(23.3)$ & $302(18.3)$ \\
\hline Median (IQR) & $2 \quad(0-9)$ & $0 \quad(0-0)$ & $(0-4)$ & sGC & $7 \quad(1.0)$ & $12 \quad(1.2)$ & $19 \quad(1.2)$ \\
\hline Emergen & & & & Any of the above 3 & $230(34.1)$ & $649(66.4)$ & $879(53.2)$ \\
\hline Any, n (\%) & $273 \quad(40.5)$ & $290 \quad(29.7)$ & $563 \quad(34.1)$ & PDE-5i, sGC) & & & \\
\hline Number of visits & & & & Exactly 1 of the 3 & 161 (23.9) & $386(39.5)$ & $547(33.1)$ \\
\hline Mean (SD) & $(1.1)$ & $(0.9)$ & $(1.0)$ & & & & \\
\hline Median (IQR) & $0 \quad(0-1)$ & $(0-1)$ & $(0-1)$ & $\geq 2$ of the 3 categories & $69(10.2)$ & $263(26.9)$ & $332(20.1)$ \\
\hline
\end{tabular}

Note: Information in this table reflects all patients newly started on prostacyclins, regardless of their duration of enrollment following initiation of prostacylins.

$E R A=$ endothelin receptor antagonist; $I Q R=$ interquartile range; $N A=$ not available; $P A H=$ pulmonary arterial hypertension; PDE-5i=phosphodiesterase type-5 inhibitor; $S D=$ standard deviation; $S G C=$ soluble guanylate cyclase. 


\section{Prostacyclin Use Among Patients with Pulmonary Arterial Hypertension in the United States: A Retrospective Analysis of a Large Health Care Claims Database}

\section{TABLE 5 Health Care Resource Utilization and Costs in the 6-Month Periods Before and After}

Prostacyclin Initiation, by Form of Prostacyclin Initiated

\begin{tabular}{|c|c|c|c|c|c|c|c|c|c|}
\hline & \multicolumn{3}{|c|}{$\begin{array}{l}\text { Parenteral Prostacyclin New-Starts } \\
\qquad(\mathrm{n}=409)\end{array}$} & \multicolumn{3}{|c|}{$\begin{array}{l}\text { Nonparenteral Prostacyclin New-Starts } \\
\qquad(\mathrm{n}=651)\end{array}$} & \multicolumn{3}{|c|}{$\begin{array}{l}\text { Any Prostacyclin New-Starts } \\
\qquad(\mathrm{n}=1,060)\end{array}$} \\
\hline & Pre-index & Post-index & $P$ Value & Pre-index & Post-index & $P$ Value ${ }^{\mathrm{a}}$ & Pre-index & Post-index & $P$ Value \\
\hline \multicolumn{10}{|c|}{ Health care resource utilization } \\
\hline \multicolumn{10}{|l|}{ Inpatient admissions } \\
\hline Any, n (\%) & $280(68.5)$ & $238(58.2)$ & $<0.001$ & $230(35.3)$ & $198(30.4)$ & 0.041 & $510 \quad(48.1)$ & $436 \quad(41.1)$ & $<0.001$ \\
\hline $\begin{array}{l}\text { Number of visits, } \\
\text { mean (SD) }\end{array}$ & $1.1 \quad(1.1)$ & $1.0 \quad(1.3)$ & 0.402 & $0.5 \quad(0.9)$ & $0.4 \quad(0.8)$ & 0.007 & $0.7 \quad(1.0)$ & $0.7 \quad(1.0)$ & 0.012 \\
\hline $\begin{array}{l}\text { Total length of } \\
\text { stay, days, } \\
\text { mean (SD) }\end{array}$ & $9.0 \quad(13.9)$ & $9.5(14.8)$ & 0.430 & $3.8(11.0)$ & $3.3(11.8)$ & 0.297 & $5.8(12.5)$ & $5.7(13.4)$ & 0.773 \\
\hline PAH-related, n (\%) & $252(61.6)$ & $219(53.5)$ & 0.004 & $199(30.6)$ & $168(25.8)$ & 0.038 & $451(42.5)$ & $387(36.5)$ & $<0.001$ \\
\hline $\begin{array}{l}\text { Number of visits, } \\
\text { mean (SD) }\end{array}$ & $0.9 \quad(0.9)$ & $0.9 \quad(1.1)$ & 0.634 & $0.4 \quad(0.7)$ & $0.3 \quad(0.6)$ & 0.029 & $0.6 \quad(0.8)$ & $0.6 \quad(0.9)$ & 0.247 \\
\hline $\begin{array}{l}\text { Total length of } \\
\text { stay, days, } \\
\text { mean (SD) }\end{array}$ & $7.7(11.2)$ & $8.6 \quad(14.4)$ & 0.173 & $3.2(10.4)$ & $2.5 \quad(8.8)$ & 0.114 & $4.9 \quad(10.9)$ & $4.9 \quad(11.7)$ & 0.799 \\
\hline \multicolumn{10}{|l|}{ Emergency room visits } \\
\hline Any, n (\%) & $209(51.1)$ & $194 \quad(47.4)$ & 0.251 & $271(41.6)$ & $223(34.3)$ & 0.003 & $480 \quad(45.3)$ & $417 \quad(39.3)$ & 0.002 \\
\hline $\begin{array}{l}\text { Number of visits, } \\
\text { mean (SD) }\end{array}$ & $1.1 \quad(1.5)$ & $1.0 \quad(1.5)$ & 0.372 & $0.8 \quad(1.2)$ & $0.7 \quad(1.2)$ & 0.071 & $0.9 \quad(1.3)$ & $0.8 \quad(1.3)$ & 0.053 \\
\hline PAH-related, n (\%) & $110(26.9)$ & $97 \quad(23.7)$ & 0.233 & $129 \quad(19.8)$ & $105 \quad(16.1)$ & 0.059 & $239(22.5)$ & $202(19.1)$ & 0.027 \\
\hline $\begin{array}{l}\text { Number of visits, } \\
\text { mean (SD) }\end{array}$ & $0.4 \quad(0.7)$ & $0.4 \quad(0.9)$ & 0.245 & $0.2 \quad(0.6)$ & $0.2 \quad(0.6)$ & 0.483 & $0.3 \quad(0.6)$ & $0.3 \quad(0.8)$ & 0.708 \\
\hline \multicolumn{10}{|l|}{ Office visits } \\
\hline Any, n (\%) & $398 \quad(97.3)$ & $402(98.3)$ & 0.344 & $643(98.8)$ & $647 \quad(99.4)$ & 0.289 & $1,041 \quad(98.2)$ & 1,049 (99.0) & 0.059 \\
\hline $\begin{array}{l}\text { Number of visits, } \\
\text { mean (SD) }\end{array}$ & $16.0(13.7)$ & $16.8(13.2)$ & 0.179 & $16.1 \quad(10.5)$ & $14.8(10.4)$ & 0.001 & $16.0 \quad(11.9)$ & $15.6(11.6)$ & 0.139 \\
\hline PAH-related, n (\%) & $340(83.1)$ & $387(94.6)$ & $<0.001$ & $607(93.2)$ & $602(92.5)$ & 0.522 & $947(89.3)$ & 989 (93.3) & $<0.001$ \\
\hline $\begin{array}{l}\text { Number of visits, } \\
\text { mean (SD) }\end{array}$ & $4.7 \quad(9.6)$ & $7.0 \quad(8.5)$ & $<0.001$ & $4.7 \quad(3.6)$ & $4.7 \quad(4.4)$ & 0.774 & $4.7 \quad(6.6)$ & $5.6 \quad(6.4)$ & $<0.001$ \\
\hline \multicolumn{10}{|c|}{ Total health care contacts } \\
\hline Any, n (\%) & $401 \quad(98.0)$ & $403(98.5)$ & 0.727 & $643(98.8)$ & $647 \quad(99.4)$ & 0.289 & $1,044 \quad(98.5)$ & $1,050 \quad(99.1)$ & 0.134 \\
\hline $\begin{array}{l}\text { Number of visits, } \\
\text { mean (SD) }\end{array}$ & $18.2(14.2)$ & $18.8(13.9)$ & 0.284 & $17.3(11.1)$ & $15.9(11.0)$ & $<0.001$ & $17.7(12.4)$ & $17.0(12.3)$ & 0.054 \\
\hline PAH-related, n (\%) & $372(91.0)$ & $389(95.1)$ & $<0.001$ & $618 \quad(94.9)$ & $618 \quad(94.9)$ & 1.000 & $990 \quad(93.4)$ & $1,007 \quad(95.0)$ & 0.038 \\
\hline $\begin{array}{l}\text { Number of visits, } \\
\text { mean (SD) }\end{array}$ & $5.9 \quad(9.8)$ & $8.3 \quad(8.9)$ & $<0.001$ & $5.4 \quad(3.8)$ & $5.2 \quad(4.6)$ & 0.423 & $5.6 \quad(6.8)$ & $6.4 \quad(6.8)$ & $<0.001$ \\
\hline \multicolumn{10}{|l|}{ Costs, \$, mean (SD) } \\
\hline \multicolumn{10}{|l|}{ Any costs } \\
\hline \multicolumn{10}{|l|}{ Medications } \\
\hline PAH medications & $6,772(13,954)$ & $46,022(48,331)$ & $<0.001$ & $20,255(21,331)$ & $91,098(48,405)$ & $<0.001$ & $15,053(19,935)$ & $73,705(53,104)$ & $<0.001$ \\
\hline $\begin{array}{l}\text { Ancillary PAH- } \\
\text { related therapies }\end{array}$ & $742 \quad(1,403)$ & $1,009 \quad(1,871)$ & $<0.001$ & $910 \quad(1,144)$ & $988 \quad(1,525)$ & 0.130 & $845 \quad(1,252)$ & $996 \quad(1,667)$ & $<0.001$ \\
\hline Other medications & $3,995(12,532)$ & $3,819(10,024)$ & 0.748 & $4,019 \quad(9,290)$ & $4,457(12,585)$ & 0.390 & $4,009(10,653)$ & $4,211 \quad(11,663)$ & 0.594 \\
\hline Total medications & $11,509(19,782)$ & $50,850(49,552)$ & $<0.001$ & $25,181(23,906)$ & $96,539(49,770)$ & $<0.001$ & $19,906(23,364)$ & $78,910(54,420)$ & $<0.001$ \\
\hline \multicolumn{10}{|l|}{ Health care contacts } \\
\hline Inpatient & $38,764(74,605)$ & $31,643 \quad(97,761)$ & 0.222 & $15,504(49,340)$ & $18,024(105,270)$ & 0.567 & $\mid 24,479(61,375)$ & $23,279(102,606)$ & 0.733 \\
\hline Emergency room & $1,389 \quad(3,820)$ & $1,008 \quad(1,943)$ & 0.053 & $1,026 \quad(3,766)$ & $932 \quad(3,034)$ & 0.594 & $1,166 \quad(3,789)$ & $961 \quad(2,665)$ & 0.122 \\
\hline Office visit & $11,587(23,947)$ & $10,090(17,327)$ & 0.050 & $9,956(16,250)$ & $7,207 \quad(17,534)$ & $<0.001$ & $10,585(19,587)$ & $8,319(17,503)$ & $<0.001$ \\
\hline $\begin{array}{l}\text { Total health care } \\
\text { contacts }\end{array}$ & $51,405(80,967)$ & $42,535(101,255)$ & 0.137 & $26,089(53,006)$ & $25,877(110,107)$ & 0.963 & $35,857(66,349)$ & $32,305(107,038)$ & 0.326 \\
\hline Other costs ${ }^{\mathrm{b}}$ & $3,309 \quad(9,730)$ & $11,345(14,671)$ & $<0.001$ & $6,845(23,775)$ & $6,158(20,423)$ & 0.385 & $5,480(19,657)$ & $8,160(18,582)$ & $<0.001$ \\
\hline Total costs & $66,224(84,473)$ & $104,729(117,666)$ & $<0.001$ & $58,114(63,594)$ & $128,427(120,938)$ & $<0.001$ & $61,243(72,437)$ & $119,283(120,186)$ & $<0.001$ \\
\hline
\end{tabular}


TABLE 5 Health Care Resource Utilization and Costs in the 6-Month Periods Before and After Prostacyclin Initiation, by Form of Prostacyclin Initiated (continued)

\begin{tabular}{|c|c|c|c|c|c|c|c|c|c|}
\hline & \multicolumn{3}{|c|}{$\begin{array}{l}\text { Parenteral Prostacyclin New-Starts } \\
(n=409)\end{array}$} & \multicolumn{3}{|c|}{$\begin{array}{l}\text { Nonparenteral Prostacyclin New-Starts } \\
(\mathrm{n}=651)\end{array}$} & \multicolumn{3}{|c|}{$\begin{array}{l}\text { Any Prostacyclin New-Starts } \\
\qquad(\mathrm{n}=1,060)\end{array}$} \\
\hline & Pre-index & Post-index & $P$ Value ${ }^{a}$ & Pre-index & Post-index & $P$ Value ${ }^{a}$ & Pre-index & Post-index & $P$ Value \\
\hline \multicolumn{10}{|l|}{ PAH-related costs } \\
\hline \multicolumn{10}{|l|}{ Medications } \\
\hline PAH medications & $6,772(13,954)$ & $46,022(48,331)$ & $<0.001$ & $20,255(21,331)$ & $91,098(48,405)$ & $<0.001$ & $15,053(19,935)$ & $73,705(53,104)$ & $<0.001$ \\
\hline $\begin{array}{l}\text { Ancillary PAH- } \\
\text { related therapies }\end{array}$ & $742 \quad(1,403)$ & $1,009 \quad(1,871)$ & $<0.001$ & $910 \quad(1,144)$ & $988 \quad(1,525)$ & 0.130 & $845 \quad(1,252)$ & $996 \quad(1,667)$ & $<0.001$ \\
\hline Total medications & $7,515 \quad(14,176)$ & $47,031(48,505)$ & $<0.001$ & $21,164(21,523)$ & $92,086(48,483)$ & $<0.001$ & $15,897(20,148)$ & $74,701(53,205)$ & $<0.001$ \\
\hline \multicolumn{10}{|l|}{ Health care contacts } \\
\hline Inpatient & $33,058(59,779)$ & $29,137(95,787)$ & 0.465 & $12,273(42,268)$ & $13,422(98,773)$ & 0.780 & $20,293(50,752)$ & $\mid 19,486(97,886)$ & 0.805 \\
\hline Emergency room & $286 \quad(1,348)$ & $363 \quad(1,177)$ & 0.389 & $(565)$ & $196 \quad(1,398)$ & 0.256 & (949) & $260 \quad(1,319)$ & 0.157 \\
\hline Office visit & $6,289(22,061)$ & $6,350 \quad(14,735)$ & 0.921 & $5,254 \quad(9,004)$ & $2,756 \quad(5,767)$ & $<0.001$ & $5,653 \quad(15,412)$ & $4,143(10,350)$ & $<0.001$ \\
\hline $\begin{array}{l}\text { Total health care } \\
\text { contacts }\end{array}$ & $39,632(63,353)$ & $35,849(97,652)$ & 0.482 & $17,657(43,098)$ & $16,375(101,108)$ & 0.759 & $26,136(52,924)$ & $23,889(100,192)$ & 0.496 \\
\hline Other costs ${ }^{b}$ & $16,901(44,403)$ & $19,663(29,570)$ & 0.243 & $16,709(39,932)$ & $17,193(51,654)$ & 0.817 & $16,783(41,694)$ & $18,146 \quad(44,452)$ & 0.387 \\
\hline Total costs & $64,048(83,861)$ & $102,543(116,977)$ & $<0.001$ & $55,528(63,115)$ & $125,531(120,350)$ & $<0.001$ & $58,815 \quad(71,915)$ & $116,661(119,530)$ & $<0.001$ \\
\hline \multicolumn{10}{|c|}{$\begin{array}{l}\text { Note: Information in this table reflects subgroup of patients newly started on prostacyclins with at least } 6 \text { months of enrollment following initiation of prostacylins. } \\
\text { a Based on paired t-tests for continuous data and McNemar's test for binary data. } \\
\text { bFor example, durable medical equipment. } \\
\text { PAH = pulmonary arterial hypertension: SD = standard deviation. }\end{array}$} \\
\hline
\end{tabular}

infection and/or potentially serious administration errors, and pain (notably with subcutaneous infusion). ${ }^{32}$ We consider it unlikely that these prescribing changes were directly influenced by guideline changes or updates. Comprehensive PH guidelines were published in 2009 (i.e., at the start of the observation period) by subspecialty societies in Europe and the United States. ${ }^{1,33}$ The most specific recommendation was for parenteral prostanoid therapy in patients presenting with FC IV symptoms. All of the then-available FDA-approved prostanoids (IV epoprostenol, IV and subcutaneous treprostinil, inhaled treprostinil, and inhaled iloprost) were included as options for "lower risk" patients.

Following the 5th World Symposium on Pulmonary Hypertension in early 2013, consensus recommendations were published in December 2013, ${ }^{14}$ but the treatment algorithm did not change significantly from the 2009 guidelines $^{1}$ for prostanoid therapy. In 2014, updated treatment guidelines from the American College of Chest Physicians made specific recommendations for prostacyclin use by FC, including the suggestions that inhaled or parenteral prostanoids not be used as first-line therapy in treatment-naive patients in FC II, that parenteral prostacyclins be used for patients in FC III with "rapid progression" or "progression" despite use of 1 or 2 classes of oral agents, and that parenteral prostanoids be used for patients in FC IV, with an inhaled formulation suggested for patients who are not candidates for or who refuse parenteral therapy. ${ }^{2}$

Of note, the most recent PH guidelines from the European Society of Cardiology and the European Respiratory Society postdated our study. ${ }^{3}$ Thus, the guideline publications during the time frame of the study did not offer any substantive change in the recommendations for the use of either parenteral or inhaled prostanoids, so they do not explain the observed trend toward inhaled prostanoids and away from parenteral formulations.

Since the parenteral and inhaled prostanoids that are FDAapproved for use in PAH were available throughout the entire study time frame, the observed shift from parenteral to inhaled formulations mainly reflects a trend toward previously available nonparenteral prostanoids rather than any significant influence of new formulations becoming available during the study period. The oral treprostinil formulation that was approved during the study time frame (in December 2013) had prescription claims only in the last 2 years of the observation period.

It remains to be seen whether the introduction of oral agents targeting the prostacyclin pathway will alter the overall percentage of patients treated with medications in this class in the future. Such change may occur with proven clinical benefit, as shown in the pivotal phase 3 trial for selexipag, which demonstrated a reduced risk for the primary composite endpoint of death or a complication related to $\mathrm{PAH}$ compared with placebo. ${ }^{34}$

Another important finding of this study is that from 2010 to 2015, patients receiving prostacyclins showed increasing use of PAH-specific medications from other drug classes. These observed treatment patterns potentially reflect the increasing focus on combination therapy in clinical practice 
guidelines. ${ }^{1,6,8,14,33}$ As the focus of our study was on patients receiving prostacyclins, we did not investigate whether patients initiating therapy with other drug classes had similar levels of augmentation from different classes; however, similar rates of presumed concomitant prostacyclin use among patients receiving ERAs and PDE-5i's were noted by Angalakuditi et al. (2010) and Berger et al. (2012). ${ }^{9,11}$

The increase we observed in health care costs in the 6 months after initiation of prostacyclin compared with the 6-month period before was largely attributable to nearly 5-fold higher costs for PAH-specific medications. While prostacyclin use may improve patient outcomes, even with the appropriate use of these or other PAH-specific drugs, the risk of hospitalization and death remains elevated in patients with $\mathrm{PAH}^{35,36}$ Owing to inherent limitations of health care claims, our study does not address whether the observed increase in the cost of treatment is accompanied by reduced morbidity and mortality, improved quality of life, and/or lower health care resource utilization and costs after the 6-month post-index period.

\section{Limitations}

The main limitation of this study is shared with all other retrospective analyses of PAH based on U.S. claims databases, in that these databases do not contain the clinical findings necessary to definitively establish a diagnosis of PAH (e.g., cardiopulmonary hemodynamics), and the codes used to identify patients with PAH are not specific, due to the lack of a unique ICD-9-CM code for PAH according to the modern classification of PH. ${ }^{19}$ Consequently, patients had to be identified based on algorithms that, while logical and consistent with how $\mathrm{PAH}$ is diagnosed and treated, may misclassify some in the sample. Although the vast majority of patients (85.5\%-93.3\%, depending on year) had the ICD-9-CM code 416.0, which maps directly to the most common subgroup of PAH (idiopathic $\mathrm{PAH}$ ), and the ascertainment algorithms required a $\mathrm{PAH}-$ related medication and/or a diagnostic test indicative of PAH, it remains possible that a proportion of patients in our sample may have had forms of $\mathrm{PH}$ other than $\mathrm{PAH}$, a potential issue identified in previous studies based on claims data. ${ }^{11}$

The databases also do not contain measures of disease severity such as FC or the 6-minute walk test, which hindered our ability to fully characterize patients receiving prostacyclins and to assess the observed prescribing patterns of prostacyclins within the framework of current guidelines. Moreover, without additional clinical information, we could not examine the degree to which switching, discontinuation, and/or augmentation occurred as a response to lack of efficacy as opposed to tolerability issues, treatment guidelines, or other concerns.

Health care claims provide information only on medications administered in physicians' offices and prescription drugs dispensed by retail pharmacies, so to the degree that patients received prostacyclins and other medications of interest while hospitalized, our findings underestimate use of these pharmacotherapies, though any such impact on the present study is likely minimal, since PAH-specific medications are dispensed mainly from specialty pharmacies. We also could not determine the correspondence between prescriptions written versus dispensed, whether medications dispensed were actually taken, and, assuming that they were taken, whether they were taken as directed.

\section{Conclusions}

From 2010 to 2015, approximately 1 in 5 PAH patients received prostacyclins. Although overall prostacyclin use was relatively unchanged, there was a shift toward nonparenteral formulations during this period. Prostacyclins were associated with increased total health care costs over the 6-month period following initiation of such therapy, largely due to higher expenditure on medications, as spending on inpatient and outpatient care remained consistent or decreased modestly. Further research is needed to better understand the benefits of prostacyclin therapy for $\mathrm{PAH}$, including positive quality-of-life impacts and the potential for reduced long-term health care costs.

\section{Authors}

CHARLES D. BURGER, MD, FCCP, Department of Medicine, Mayo Clinic, Jacksonville, Florida. JANIS A. PRUETT, EdD, MSN, FNP-BC; CASSANDRA A. LICKERT, MD; and WILLIAM DRAKE, III, PharmD, Actelion Pharmaceuticals US, South San Francisco, California. ARIEL BERGER, MPH, and BRIAN MURPHY, MS, Evidera, Waltham, Massachusetts.

AUTHOR CORRESPONDENCE: Charles D. Burger, MD, FCCP, 4500 San Pablo Rd., S., Jacksonville, FL 32224. Tel.: 904.953.2869; E-mail: burger.charles@mayo.edu.

\section{DISCLOSURES}

This research was funded by Actelion Pharmaceuticals US, a Janssen pharmaceutical company of Johnson \& Johnson. Burger has received grant funding from Actelion, Gilead Sciences, and United Therapeutics; personal fees from Actelion and Gilead Sciences; and nonfinancial support from Actelion. Pruett, Lickert, and Drake are employees of Actelion. Pruett and Lickert own shares in Actelion. Berger and Murphy are employees of Evidera, a consultancy that received payment from Actelion to conduct this research.

Pruett, Lickert, Berger, and Drake contributed to study conception and participated with Burger in study design. Lickert and Murphy performed the data analyses. Burger, Pruett, Lickert, Murphy, and Drake interpreted the data. All authors participated in manuscript drafting and/or critical revision, approved the final manuscript, and agree to be accountable for all aspects of the work. 


\section{ACKNOWLEDGMENTS}

The authors thank Philip Rotella for contributing to the data analyses. Medical writing and editorial support were provided by W. Mark Roberts, $\mathrm{PhD}$, Montréal, Québec, Canada, with funding by Actelion.

\section{REFERENCES}

1. Galiè N, Hoeper MM, Humbert M, et al. Guidelines for the diagnosis and treatment of pulmonary hypertension: the Task Force for the Diagnosis and Treatment of Pulmonary Hypertension of the European Society of Cardiology (ESC) and the European Respiratory Society (ERS), endorsed by the International Society of Heart and Lung Transplantation (ISHLT). Eur Heart J. 2009;30(20):2493-537.

2. Taichman DB, Ornelas J, Chung L, et al. Pharmacologic therapy for pulmonary arterial hypertension in adults: CHEST guideline and expert panel report. Chest. 2014;146(2):449-75.

3. Galiè N, Humbert M, Vachiery JL, et al. 2015 ESC/ERS Guidelines for the diagnosis and treatment of pulmonary hypertension: The Joint Task Force for the Diagnosis and Treatment of Pulmonary Hypertension of the European Society of Cardiology (ESC) and the European Respiratory Society (ERS): Endorsed by: Association for European Paediatric and Congenital Cardiology (AEPC), International Society for Heart and Lung Transplantation (ISHLT). Eur Heart J. 2016;37(1):67-119.

4. Barst R. How has epoprostenol changed the outcome for patients with pulmonary arterial hypertension? Int J Clin Pract Suppl. 2010;64(168):23-32.

5. Humbert M, Ghofrani HA. The molecular targets of approved treatments for pulmonary arterial hypertension. Thorax. 2016;71(1):73-83.

6. Hill NS, Cawley MJ, Heggen-Peay CL. New therapeutic paradigms and guidelines in the management of pulmonary arterial hypertension. J Manag Care Spec Pharm. 2016;22(3 Suppl A):S3-21. Available at: http://www.jmcp. org/doi/10.18553/jmcp.2016.22.3-a.s3.

7. Barst RJ, Rubin LJ, Long WA, et al. A comparison of continuous intravenous epoprostenol (prostacyclin) with conventional therapy for primary pulmonary hypertension. N Engl J Med. 1996;334(5):296-301.

8. Barst RJ, Gibbs JS, Ghofrani HA, et al. Updated evidence-based treatment algorithm in pulmonary arterial hypertension. J Am Coll Cardiol. 2009;54 (1 Suppl):S78-84

9. Angalakuditi M, Edgell E, Beardsworth A, Buysman E, Bancroft T. Treatment patterns and resource utilization and costs among patients with pulmonary arterial hypertension in the United States. J Med Econ. 2010;13(3):393-402

10. Copher R, Cerulli A, Watkins A, Laura Monsalvo M. Treatment patterns and healthcare system burden of managed care patients with suspected pulmonary arterial hypertension in the United States. J Med Econ. 2012;15(5):947-55.

11. Berger A, Edelsberg J, Teal S, Mychaskiw MA, Oster G. Changes in healthcare utilization and costs associated with sildenafil therapy for pulmonary arterial hypertension: a retrospective cohort study. BMC Pulm Med. 2012;12(1):75.

12. Berger A, Edelsberg J, Teal S, Mychaskiw MA, Oster G. Use of sildenafil in pulmonary arterial hypertension: findings from a U.S. healthcare claims database. J Health Econ Outcomes Res. 2014;1(3):254-65.

13. Enderby CY, Burger C. Medical treatment update on pulmonary arterial hypertension. Ther Adv Chronic Dis. 2015;6(5):264-72.

14. Galiè N, Corris PA, Frost A, et al. Updated treatment algorithm of pulmonary arterial hypertension. J Am Coll Cardiol. 2013;62(25 Suppl):D60-72.

15. Farber HW, Miller DP, Meltzer LA, McGoon MD. Treatment of patients with pulmonary arterial hypertension at the time of death or deterioration to functional class IV: insights from the REVEAL Registry. J Heart Lung Transplant. 2013;32(11):1114-22
16. Truven Health Analytics. MarketScan studies: abbreviated bibliography May 20, 2016. Available at: http://truvenhealth.com/Portals/0/Assets/LifeSciences/Bibliographies/2016-Truven-Health-MarketScan-Bibliography.pdf. Accessed November 18, 2017.

17. Said Q, Martin BC, Joish VN, Kreilick C, Mathai SC. The cost to managed care of managing pulmonary hypertension. J Med Econ. 2012;15(3):500-08

18. Burudpakdee C, Shah A, Joish VN, Divers C, Yaldo A. Budgetary impact of adding riociguat to a US health plan for the treatment of patients with pulmonary arterial hypertension or chronic thromboembolic pulmonary hypertension. Am Health Drug Benefits. 2014;7(9):479-87.

19. Link J, Glazer C, Torres F, Chin K. International Classification of Diseases coding changes lead to profound declines in reported idiopathic pulmonary arterial hypertension mortality and hospitalizations: implications for database studies. Chest. 2011;139(3):497-504.

20. Burke JP, Hunsche E, Regulier E, Nagao M, Buzinec P, Drake III W. Characterizing pulmonary hypertension-related hospitalization costs among Medicare Advantage or commercially insured patients with pulmonary arterial hypertension: a retrospective database study. Am J Manag Care. 2015;21(3 Suppl):s47-58.

21. Kirson NY, Birnbaum HG, Ivanova JI, Waldman T, Joish V, Williamson $\mathrm{T}$. Excess costs associated with patients with pulmonary arterial hypertension in a US privately insured population. Appl Health Econ Health Policy. 2011;9(5):293-303.

22. Quan H, Sundararajan V, Halfon P, et al. Coding algorithms for defining comorbidities in ICD-9-CM and ICD-10 administrative data. Med Care. 2005;43(11):1130-39

23. Deyo RA, Cherkin DC, Ciol MA. Adapting a clinical comorbidity index for use with ICD-9-CM administrative databases. J Clin Epidemiol. 1992;45(6):613-19.

24. U.S. Department of Labor, Bureau of Labor Statistics. Databases, tables $\&$ calculators by subject: 2005-2015, medical care. 2015. Available at: http:// data.bls.gov/timeseries/CUUR0000SAM?output_view=pct_12mths. Accessed November 18, 2017

25. Express Scripts. 2015 drug trend report. March 2016. Available at: https://lab.express-scripts.com/lab/ /media/e2c9d19240e94fcf893b706el3068750.ashx. Accessed November 18, 2017.

26. Johnson S, Delate T, Boka A, Shaw P, Zager C. Characterizing the financial burden of pulmonary arterial hypertension within an integrated healthcare delivery system. J Med Econ. 2013;16(12):1414-22.

27. Dufour R, Pruett J, Lane D, et al. Pulmonary arterial hypertension (PAH): real-world treatment patterns, outcomes and costs based on World Health Organization (WHO) functional class (FC). Value Health. 2015;18(7):A498-99.

28. Badesch DB, Raskob GE, Elliott CG, et al. Pulmonary arterial hypertension: baseline characteristics from the REVEAL Registry. Chest. 2010;137(2):376-87.

29. Hay BR, Pugh ME, Robbins IM, Hemnes AR. Parenteral prostanoid use at a tertiary referral center: a retrospective cohort study. Chest. 2016;149(3):660-66.

30. Tonelli AR, Dweik RA. Why patients who die of worsening pulmonary arterial hypertension are not on parenteral prostacyclin analog treatment? J Heart Lung Transplant. 2014;33(2):221.

31. Tonelli AR, Arelli V, Minai OA, et al. Causes and circumstances of death in pulmonary arterial hypertension. Am J Respir Crit Care Med. 2013;188(3):365-69.

32. Burger CD, D’Albini L, Raspa S, Pruett JA. The evolution of prostacyclins in pulmonary arterial hypertension: from classical treatment to modern management. Am J Manag Care. 2016;22(1 Suppl):S3-15. 
Prostacyclin Use Among Patients with Pulmonary Arterial Hypertension in the United States:

A Retrospective Analysis of a Large Health Care Claims Database

33. McLaughlin VV, Archer SL, Badesch DB, et al. ACCF/AHA 2009 expert consensus document on pulmonary hypertension: a report of the American College of Cardiology Foundation Task Force on Expert Consensus Documents and the American Heart Association: developed in collaboration with the American College of Chest Physicians, American Thoracic Society, Inc., and the Pulmonary Hypertension Association. Circulation. 2009;119(16):2250-94

34. Sitbon O, Channick R, Chin KM, et al. Selexipag for the treatment of pulmonary arterial hypertension. N Engl J Med. 2015;373(26):2522-33.
35. Burger CD, Long PK, Shah MR, et al. Characterization of first-time hospitalizations in patients with newly diagnosed pulmonary arterial hypertension in the REVEAL registry. Chest. 2014;146(5):1263-73.

36. Frantz RP, Schilz RJ, Chakinala MM, et al. Hospitalization and survival in patients using epoprostenol for injection in the PROSPECT observational study. Chest. 2015;147(2):484-94. 
Prostacyclin Use Among Patients with Pulmonary Arterial Hypertension in the United States:
A Retrospective Analysis of a Large Health Care Claims Database

\section{APPENDIX A Claims Database Codes Used to Ascertain PAH Patients, Procedures, and Drugs}

\begin{tabular}{|c|c|}
\hline Diagnosis, Procedure, or Drug & Definition \\
\hline $\mathrm{PAH}$ & ICD-9-CM diagnoses 416.0, 416.8, 416.9 \\
\hline Heart catheterization & $\begin{array}{l}\text { ICD-9-CM procedures 37.21, 37.23, 89.63, 89.64; CPT procedures 93451, 93453, 93456, 93460, 93501, } \\
93526\end{array}$ \\
\hline Cardiac surgery & ICD-9-CM procedures 35.4, 35.41, 35.42; CPT procedures 33737, 33735, 33736, 92992, 92993 \\
\hline Echocardiogram & $\begin{array}{l}\text { ICD-9-CM procedure 88.72; CPT procedures 93350, 93351, 93303, 93304, 93306, 93307, 93308, 93312, } \\
\text { 93313, 93314, 93315, 93316, } 93317\end{array}$ \\
\hline Transplant & ICD-9-CM procedures 33.5, 33.50, 33.51, 33.52, 33.6; CPT procedures 32851, 32852, 32853, 32854, 33935 \\
\hline Ventilation-perfusion scan & CPT procedures 78580,78585 \\
\hline Cardiac computed tomography angiography & CPT procedures $75571-75574,75571,75572,75573$ \\
\hline $\begin{array}{l}\text { Epoprostenol (Veletri, Flolan, } \\
\text { Epoprostenol) }\end{array}$ & $\begin{array}{l}\text { HCPCS codes J1325, S0155; NDC numbers 0703-1985, 0703-1995, 66215-401, 66215-402, 66215-403, } \\
0173-0517,0173-0519\end{array}$ \\
\hline Iloprost (Ventavis) & HCPCS codes Q4080, Q4074; NDC numbers 66215-302, 66215-303 \\
\hline $\begin{array}{l}\text { Treprostinil (Remodulin, Tyvaso, } \\
\text { Orenitram) }\end{array}$ & $\begin{array}{l}\text { HCPCS codes J3285, Q4077, S0114, J7686; NDC numbers 66302-101, 66302-102, 66302-105, 66302-110, } \\
66302-206,66302-300,66302-302,66302-310,66302-325\end{array}$ \\
\hline Bosentan (Tracleer) & NDC numbers 66215-101, 66215-102 \\
\hline Ambrisentan (Letairis) & NDC numbers 61958-0801, 61958-0802 \\
\hline Macitentan (Opsumit) & NDC numbers 66215-501 \\
\hline Sildenafil (Revatio, Viagra) & $\begin{array}{l}\text { HCPCS codes J3490, S0090; NDC numbers 63629-5029, 65162-351, 67544-355, 67544-356, 68001-176, } \\
68084-622,16714-338,21695-157,21695-158,33342-121,0069-0336,0069-0338,0069-4190,0069-4200, \\
0069-4210,0069-4220,0093-5517,0179-0160,0378-1657,0591-3780,13668-185,42291-730,43063-256, \\
43063-550,43353-764,49999-316,51655-131,52125-494,52125-710,54868-4084,54868-4706, \\
54868-4784,55111-372,55154-2727,55154-2729,55154-2736,55289-524,55289-577,59762-0033, \\
60505-3404,63539-421,63539-422,63629-1792,63629-2640\end{array}$ \\
\hline Tadalafil (Adcirca, Cialis) & $\begin{array}{l}\text { NDC numbers 16590-905, 21695-028, 21695-029, 0002-4462, 0002-4463, 0002-4464, 0002-4465, } \\
43063-236,43353-857,54868-4665,54868-4968,54868-5956,55154-1830,63629-2734,63629-4145 \\
63629-4601,66302-467,66336-566\end{array}$ \\
\hline Vardenafil (Levitra, Staxyn ODT) & $\begin{array}{l}\text { NDC numbers 0179-0102, 43353-323, 43353-741, 43353-744, 43353-748, 54868-4967, 54868-4984, } \\
54868-6333,55289-193,55289-194,67544-507,67544-512,0173-0822,0173-0828,0173-0829, \\
0173-0830,0173-0831,63629-3372\end{array}$ \\
\hline Riociguat (Adempas) & NDC numbers 50419-250, 50419-251, 50419-252, 50419-253, 50419-254 \\
\hline
\end{tabular}

CPT-4 = Current Procedural Terminology-4; HCPCS = Healthcare Common Procedure Coding System; ICD-9-CM=International Classification of Diseases, Ninth Revision, Clinical Modification; $N D C=$ National Drug Code; $P A H=$ pulmonary arterial hypertension . 
Prostacyclin Use Among Patients with Pulmonary Arterial Hypertension in the United States:

A Retrospective Analysis of a Large Health Care Claims Database

\section{APPENDIX B Characteristics of Patients in the Pre-Post Analysis Cohort Before the Index Date, by Form of} Prostacyclin Initiated

\begin{tabular}{|c|c|c|c|}
\hline Characteristic & $\begin{array}{c}\text { Parenteral Prostacyclin } \\
\text { New-Starts }\end{array}$ & $\begin{array}{c}\text { Nonparenteral Prostacyclin } \\
\text { New-Starts }\end{array}$ & $\begin{array}{c}\text { Any Prostacyclin } \\
\text { New-Starts (Fully Naive) }\end{array}$ \\
\hline Number & 409 & 651 & 1,060 \\
\hline \multicolumn{4}{|l|}{ Age, years } \\
\hline Mean (SD) & $54.3 \quad(13.4)$ & $(13.5)$ & $(13.8)$ \\
\hline Median (IQR) & $55 \quad(46-62)$ & $62 \quad(52-71)$ & $59 \quad(50-68)$ \\
\hline Range & $18-90$ & $18-90$ & $18-90$ \\
\hline \multicolumn{4}{|l|}{ Gender, n (\%) } \\
\hline Male & $(26.9)$ & $(31.2)$ & $(29.5)$ \\
\hline Female & $299 \quad(73.1)$ & $448 \quad(68.8)$ & $(70.5)$ \\
\hline \multicolumn{4}{|l|}{ Payer type, n (\%) } \\
\hline Commercial & $(79.2)$ & $(58.4)$ & $(66.4)$ \\
\hline Medicare & $(20.8)$ & $(41.6)$ & (33.6) \\
\hline \multicolumn{4}{|l|}{ Charlson Comorbidity Index } \\
\hline Mean (SD) & $(1.8)$ & $(2.0)$ & (1.9) \\
\hline Median (IQR) & $(2-4)$ & $(1-4)$ & (1-4) \\
\hline \multicolumn{4}{|l|}{ Comorbidities, n (\%) } \\
\hline Depressive disorders & $(11.2)$ & $(9.5)$ & $(10.2)$ \\
\hline Anxiety disorders & $(9.0)$ & $(5.2)$ & $(6.7)$ \\
\hline Sleep disorders & $(15.2)$ & $(14.9)$ & $(15.0)$ \\
\hline Cerebrovascular disease & $(6.6)$ & $(7.7)$ & $(7.3)$ \\
\hline Peripheral vascular disease & $(6.8)$ & $(5.2)$ & $(5.8)$ \\
\hline Coronary heart disease & $(30.3)$ & $(30.3)$ & $(30.3)$ \\
\hline Atrial fibrillation & $(0.0)$ & $(0.0)$ & $(0.0)$ \\
\hline Raynaud's syndrome & $(0.0)$ & $(0.0)$ & $(0.0)$ \\
\hline Hematological conditions & $(1.5)$ & $(0.8)$ & $(1.0)$ \\
\hline Liver disease & $(13.2)$ & $(10.9)$ & $(11.8)$ \\
\hline Renal disease & $(36.7)$ & $(28.4)$ & $(31.6)$ \\
\hline Diabetes & $(24.9)$ & $(27.8)$ & $(26.7)$ \\
\hline Neoplasms & $(14.4)$ & $(14.9)$ & $(14.7)$ \\
\hline
\end{tabular}

